Revista de

Contabilidade e

Organizações

www.rco.usp.br
DOI: http://dx.doi.org/10.11606/rco.v11i31.134465
Journal of

Accounting and

Organizations

www.rco.usp.br

\title{
Sobre corruptos, corrompidos e culpados: relatos de servidores públicos sobre práticas de corrupção
}

Corrupt, corrupted, culprit: civil servants 'narratives on corruptive practices

Rachel Juliene Menezes Sodréa

${ }^{a}$ Universidade Federal de Minas Gerais

Palavras-chave

Práticas de corrupção.

Comportamento desviante no trabalho.

Setor público.

\begin{abstract}
Resumo
Este artigo analisa possíveis articulações entre comportamentos desviantes no trabalho e a ocorrência de práticas de corrupção em organizações do setor público. A partir dos relatos de servidores públicos de um governo estadual, foram observadas as percepções e experiências desses servidores em relação a atos de corrupção. A literatura sobre comportamentos desviantes no trabalho sugere que as práticas de corrupção nas organizações variam de um grau de desvio de comportamento grave a aceitável. No caso analisado, as evidências indicam o uso de mecanismos de aceitação e perpetuação de práticas de corrupção, como um posicionamento oficial de negação de que tenha ocorrido corrupção e uso de processos informais para tratar denúncias, como investigação e atribuição de sanções a delatores e delatados.
\end{abstract}

\begin{abstract}
This paper analyses possible connections between deviant workplace behavior and the occurrence of corruptive practices in public sector organizations. Based on narrative data from civil servants of a Brazilian state government, we observed their perceptions and experiences regarding acts of corruption. The literature on deviant workplace behavior suggests that corruptive practices vary in degree of deviance behavior from grave to acceptable. In this article, the evidences indicate the use of mechanisms of acceptance and perpetuation of corruptive practices, such as an official position denying the corruption occurrence, and the use of informal processes to deal with such cases, as to investigate and punish informers and defendants.
\end{abstract}

\section{Implicações práticas}

As práticas de corrupção em organizações ocorrem misturadas com outros desvios de comportamento. No caso analisado tais desvios permaneceram sem um tratamento sistemático e formal, comentados informalmente, que se mantém pelo silêncio da governança. Organizações do setor público podem criar mecanismos para reduzir estas condições que ajudam a proliferar tais comportamentos.

Copyright (C) 2017 FEA-RP/USP. Todos os direitos reservados

\section{INTRODUCC̃̃O}

São muitas as abordagens para analisar o fenômeno 'corrupção', o que se reflete na ausência de um consenso sobre sua definição. Brei (1996), por exemplo, ressalta que o termo pode incluir uma grande variedade de atos, como falsificação, suborno, extorsão, dentre outros. Nesse sentido, as definições sobre corrupção variariam conforme as perspectivas teóricas que a embasam, tais como teorias jurídicas, econômicas e políticas.

Há, no entanto, certa associação entre corrupção e o setor público: embora parta de posicionamentos diferentes, um traço comum às teorias sobre corrupção é considerá-la como a sobreposição dos interesses privados ao interesse público, visando a obtenção de vantagens (Filgueiras, 2004). Tais definições, porém, seriam limitadas em função de não levarem em consideração certos valores compartilhados na esfera pública. Em vista disso, Filgueiras (2009) propõe a análise da corrupção a partir da antinomia entre normas morais e prática social: a corrupção estaria relacionada à "constituição de normas informais que institucionalizam certas práticas tidas como moralmente degradantes, mas cotidianamente toleradas" (Filgueiras, 2009, p. 387). 
Nesta perspectiva, ocorreriam outras situações corruptivas que não se amoldam perfeitamente à dimensão econômica de obtenção de vantagem ou benefício, ou à dimensão jurídico-normativa que restringiria a prática de corrupção a ilicitudes ou a problemas meramente jurídicos. Isso significa dizer que analisar a corrupção passaria pelo entendimento da configuração dos aspectos normativos que a fundamentam. Dessa forma, a corrupção pode ser entendida como aquilo que é considerado o rompimento de uma orientação normativa (Filgueiras, 2009). E essa orientação é construída com o estabelecimento de certos juízos acerca do comportamento dos atores e das organizações.

Dessa forma, propõe-se analisar práticas de corrupção a partir das contribuições teóricas sobre comportamentos desviantes no trabalho. Para diversos autores (Anand, Ashforth \& Joshi, 2005; Pinto, Leana \& Píl, 2008; Robinson \& Bennett, 1995) há certa sobreposição entre a ideia de corrupção e a ideia de comportamento desviante: a corrupção seria o mau uso de determinada posição ou autoridade na organização para ganho pessoal ou até mesmo organizacional, no qual o "mau uso" estaria relacionado ao afastamento das normas entendidas como adequadas. Assim, o objetivo geral deste artigo é investigar possíveis articulações entre comportamentos desviantes no trabalho e a ocorrência de práticas de corrupção no setor público. Para tanto, utiliza-se o relato de servidores públicos de um governo estadual, analisando-se suas percepções e experiências sobre as práticas de corrupção observadas por eles na organização. Com isto, são abordadas algumas ocorrências comuns e as formas de tratamento daqueles eventos.

\section{COMPORTAMENTOS DESVIANTES NAS ORGANIZACÕES}

Em estudos organizacionais, a literatura acerca de comportamentos nas organizações enfatizou, até o início da década de 1990, construtos que destacavam atitudes e condutas positivas no trabalho, a exemplo das noções de comprometimento e satisfação. A partir de meados dos anos 1990, porém, emergiram mais estudos sobre comportamentos negativos no âmbito organizacional (Robinson \& Bennett, 1995). Embora tenham características em comum, há grande variedade nos conceitos de comportamentos negativos, tais como: má conduta nas organizações, comportamento antissocial, comportamento disfuncional, comportamento contraproducente, comportamento antiético, incivilidade e comportamento agressivo no trabalho (Appelbaum, Iaconi \& Matousek, 2007). Um denominador comum a tais conceitos é a ideia de divergência entre normas colocadas e a conduta do indivíduo.

Para os propósitos deste trabalho, utiliza-se o termo 'comportamento desviante no trabalho' (Robinson \& Bennett, 1995; Warren, 2003) para indicar a ação de indivíduos ou grupo de indivíduos na organização, que configure uma violação voluntária de alguma norma tida como referência. Internamente, tais indivíduos podem violar políticas, diretrizes, costumes ou regulamentos próprios daquela organização. Há, também, a possibilidade de desvio de normas referenciais mais amplas, como valores e princípios socialmente considerados adequados (Warren, 2003). Trata-se de uma definição um tanto generalista, podendo abarcar tanto desvios negativos quanto positivos. Os desvios negativos são aqueles que podem resultar em prejuízos para a organização, seus membros ou ambos. Desvios de comportamento em organizações do setor público e o consequente mau uso do recurso público e ineficiência de forma geral geram prejuízo também aos beneficiários dos serviços.

O comportamento desviante positivo, menos pesquisado, é conduta intencional que se afasta de forma honrosa das normas do grupo de referência (Spreitzer \& Sonenshein, 2004). Tais comportamentos desviantes positivos incluem condutas inovadoras, desobediência a regras disfuncionais ou mesmo criticar superiores inábeis no desempenho de suas funções (Appelbaum et al., 2007). No caso, são enfatizados atos cometidos com boas intenções, a despeito dos seus resultados. Destaca-se que uma 'intenção honrosa' é avaliada em relação às outras condutas tipicamente esperadas do grupo; assim as interpretações a respeito do ato podem não ser consensuais.

De todo modo, é possível fazer uma aproximação entre comportamentos desviantes e práticas de corrupção, uma vez que ambos se referem à ruptura de uma orientação normativa. Esta ruptura, no entanto, não seria estática: a corrupção seria tanto um estado quanto um processo, que se desenrola a partir de dinâmicas de interação entre indivíduos, grupos e organizações (Ashforth et al., 2008). Disso decorre uma pluralidade de abordagens sobre o fenômeno que tratam de variáveis como o tipo de violação, a extensão do dano e o perfil dos atores envolvidos (Pinto et al., 2008).

Para subsidiar a análise da natureza de comportamentos desviantes, são ressaltados dois modelos analíticos: o de Robinson e Bennett (1995), que sistematizam condutas desviantes quanto à gravidade do ato e para onde o ato está direcionado; e o de Pinto et al. (2008), que diferenciam tipos de conduta desviante a partir de duas dimensões: o principal beneficiário da prática e o tipo de ligação estabelecida entre os membros da organização. 
A tipologia de Robinson e Bennett (1995) é composta por quatro tipos de comportamento desviante, resultado da combinação de duas dimensões analíticas: leve vs séria, referindo-se à gravidade do ato; e organizacional $v s$ interpessoal, referindo-se ao "alvo" do comportamento desviante. Dessa forma, 'desvios de propriedade' seriam comportamentos de maior gravidade com prejuízos à organização. Nesta primeira categoria estariam condutas como o dano intencional a recursos da organização; a apropriação de bens da organização e o aceite de suborno ou propina. Tais condutas se assemelham à descrição de diversos crimes praticados contra a Administração Pública, como corrupção strictu sensu, improbidade administrativa, peculato e emprego irregular de bens públicos.

A segunda categoria de comportamentos desviantes é denominada desvio de produção, entendida como condutas que causam prejuízo à organização, mas com menor gravidade. Estariam nesta categoria o desperdício de recursos para realização de determinada tarefa, a redução intencional e injustificada do trabalho ou o não cumprimento da jornada de trabalho (Robinson \& Bennett, 1995).

O desvio político, como terceira categoria, seria o comportamento de menor gravidade contra os membros de uma organização, colocando-os em desvantagem pessoal ou política. Os comportamentos desta categoria incluem favoritismo, disseminação de fofocas ou rumores sobre colegas de trabalho e competição não benéfica entre indivíduos ou grupos da organização (Appelbaum et al., 2007; Robinson \& Bennett, 1995).

Por fim, a quarta categoria da tipologia é denominada agressão pessoal. Seria comportamentos negativos (agressivos ou hostis) graves contra membros da própria organização, incluindo abuso verbal, assédio moral e sexual (Appelbaum et al., 2007; Robinson \& Bennett, 1995).

Quanto à tipologia de Pinto et al. (2008), realiza-se, primeiramente, uma distinção entre o beneficiário de condutas desviantes, podendo ser o indivíduo (ou pequeno grupo) ou a organização em si. O benefício mencionado por estes autores é, primariamente, de ordem pecuniária, como apropriação indébita, propina e suborno, embora não descartem vantagens de ordem imaterial ou simbólica. A segunda dimensão se refere à possibilidade de conluio ou conchavo (collusion) entre membros da organização. Pinto et al. (2008) argumentam que a prática de atos de corrupção visando benefícios para a organização é possível quando há referido conluio, especialmente se for entre membros da alta cúpula organizacional.

A partir dessas dimensões, Pinto et al. (2008) sugerem dois tipos de corrupção no âmbito organizacional. A primeira delas é a organização de indivíduos corruptos, definida como um fenômeno bottom-up, no qual prevalece a busca de vantagens para os indivíduos por meio de condutas desviantes (Ashforth et al., 2008). O segundo tipo é a organização corrupta, entendida como um fenômeno top-down no qual um grupo da organização, geralmente a coalizão dominante, cúpula organizacional ou altos gestores, promovem ações consideradas corruptas, diretamente ou por meio de seus subordinados, visando à obtenção de benefícios para a organização (Pinto et al., 2008).

\section{METODOLOGIA}

O estudo foi realizado a partir de entrevistas com servidores públicos de duas secretarias de um governo estadual, por meio de um roteiro semiestruturado. Dado o foco em percepções sobre corrupção, optou-se por este tipo de entrevista por permitir certa liberdade ao participante no desenvolvimento das respostas, mesmo em face de um conjunto de perguntas previamente definido.

As perguntas do roteiro abordaram quatro tópicos: a) concepção do servidor sobre corrupção; b) percepções sobre práticas de desvio (se seria algo disseminado ou localizado na organização, se já ouviu casos, se já reportou alguma prática de corrupção ou desvio); c) formas de abordagem do evento (como as informações são disseminadas na organização, como é o tratamento dos servidores, se há canais ou fluxos conhecidos e seguidos); e d) possibilidades de mudança (se algum processo, estrutura, prática ou atitude poderia ser melhorado ou implantado). As perguntas principais foram complementadas por outras questões suscitadas no momento da entrevista, conforme a fala do entrevistado.

Foram selecionados servidores públicos das áreas de saúde, segurança pública e educação, com mais de três anos de experiência profissional, ocupantes de cargos técnicos dos setores de planejamento estratégico/ desenvolvimento organizacional de suas respectivas organizações. Optou-se por este perfil de servidor por sua inserção profissional diferenciada, mais próxima da cúpula das organizações. Considerando que suas atribuições incluem elaborar e validar o planejamento de toda a organização, monitorar o cumprimento de metas setoriais e assessorar a chefia na tomada de decisões, estes profissionais têm uma visão abrangente da dinâmica de funcionamento da organização. Não foi feita distinção, a priori, entre servidores efetivos e não efetivos, uma vez que ambos desempenham as mesmas atividades em seus respectivos setores. 
Os convites foram realizados por e-mail, no qual era informado o propósito da pesquisa e o tema. Em havendo concordância, era encaminhado o termo de consentimento. Dos seis convites enviados, houve três aceites: dois da área de segurança pública e um da área de saúde. No momento das entrevistas, os respondentes exerciam cargos de assessoria estratégica (vinculados à chefia das organizações), tendo de quatro a nove anos de experiência profissional.

As entrevistas, com duração média de trinta minutos foram realizadas durante o mês de fevereiro de 2016, tendo sido gravadas. Mesmo com a participação voluntária, observou-se certo desconforto entre os participantes, especialmente para a verbalização de episódios específicos sobre comportamentos desviantes. Foi comum períodos de silêncio durante os relatos, a diminuição do tom de voz (mesmo as entrevistas tendo sido conduzidas em lugares reservados, com a presença apenas da pesquisadora e do entrevistado), e uma formulação muito cuidadosa das respostas. Considerando a criticidade do tema, e a fim de preservar a identidade dos participantes, a referência a eles será feita apenas por servidor da área da saúde ou da segurança pública (1 e 2) quando trechos de seus depoimentos forem citados.

Para tratamento dos dados, os depoimentos foram, inicialmente, analisados individualmente, tendo como guia referencial os tópicos previamente definidos pelo roteiro. A partir deles, foram estabelecidas categorias, tais como concepção de corrupção, casos de corrupção, divulgação de informações sobre práticas desviantes, etc., de forma a compilar e organizar trechos significativos das entrevistas. Em seguida, trabalhou-se com o conjunto do material, associando ideias e trechos semelhantes sob tais categorias, das quais foram selecionados os momentos narrativos expostos na próxima seção.

Para sistematização dos achados, os trechos dos relatos foram agrupados, posteriormente, nos quatro temas expostos a seguir, referentes a práticas consideradas desviantes e que têm influência sobre a identificação, tratamento e perpetuação de corrupção no âmbito das organizações.

\section{RESULTADOS E DISCUSSÃO}

A seção apresenta os resultados da pesquisa, agregando os relatos dos servidores; e então analisa de que forma tais relatos assinalam para uma superposição entre certos comportamentos desviantes no trabalho e o que seria entendido como corrupção. Aponta, ainda, os mecanismos utilizados para que essas condutas sejam conhecidas e abordadas.

\subsection{Comportamentos desviantes como práticas de corrupção}

Inicialmente, ao serem perguntados sobre o que poderia constituir práticas de corrupção, os respondentes indicaram condutas tipificadas como crimes, isto é, atos pré-definidos aos quais o ordenamento jurídico-penal prevê a atribuição de sanções, caso ocorram. Nesse aspecto, foram apontadas não apenas condutas que seriam definidas, em sentido jurídico estrito, como corrupção, mas também outros crimes praticados contra a Administração Pública:

Eu acho que teriam modalidades, talvez desviar dinheiro público, acho que está mais ligado a isso, eu acho que se aproveitar de determinada posição também, basicamente, tirar vantagens (Servidor da área da saúde).

[...] qualquer tipo de prática para desvio de verba, utilização indevida de recurso público para benefício próprio. Principalmente essa parte voltada ao recurso público eu acho que é o tipo de corrupção mais grave no serviço público, porque eu acho que tem outras (Servidor da área de segurança pública 2).

Em seguida, porém, os entrevistados elencaram outras condutas que, embora não fossem necessariamente ilícitas, poderiam ser entendidas como corruptas, a partir da ideia de obtenção de uma vantagem indevida:

Eu entendo que corrupção é um comportamento inadequado, indevido, ilegal, às vezes nem sempre ilegal, mas imoral, no sentido de que você vai levar vantagem de alguma forma. Eu acho que quando a pessoa tem alguma atitude que não seja legal ou moral pra tomar vantagem de alguma coisa, eu entendo como corrupção (Servidor da área de segurança pública 2).

Definiria corrupção como uma espécie de um desvio, né, desvio de conduta no trabalho, ai, é uma dificuldade definir isso... Seria um desvio e tudo aquilo que não estaria inserido dentro dos comportamentos legais de uma organização. [...] Diversos atos do próprio servidor, sejam eles comportamentos, desde o horário que chega ou da forma como ele executa determinada atividade... A capacidade que às vezes o servidor tem de analisar o outro sem levar em consideração o próprio comportamento. Então tentando tirar vantagem, às vezes, do serviço do outro... O problema é lembrar todas elas, mas o principal seria isso (Servidor da área de segurança pública 1). 
Interessante notar que a obtenção de vantagem nem sempre se materializaria em benefício financeiro; outras formas menos visíveis, como a redução intencional e injustificada da jornada de trabalho ou da qualidade dos produtos a ser entregues (como relatórios, projetos, atendimentos, etc.) seriam também consideradas indevidas:

No setor público eu acho mais grave porque está se tratando de recursos da população, não é de uma ou de duas pessoas: você vai numa empresa familiar; roubou; você vai ter todas as penalidades, você está prejudicando uma pessoa. No caso do setor público você está prejudicando uma população inteira (Servidor da área de segurança pública 2).

Seria totalmente disseminado, em todas as esferas e em todos os poderes, no Executivo, no Legislativo e no Judiciário, eu acho que é endêmico no Brasil [...] Na sociedade a corrupção do setor público é muito prejudicial por estar em todas as esferas, todos os âmbitos (Servidor da área de saúde).

No serviço público você vê muito disso, pessoas que você vê que estão ali só para enfeitar, e que está de certa forma tirando vantagem daquilo que é o que o cidadão espera dele como servidor público (Servidor da área de segurança pública 1).

Nesta perspectiva, parece haver uma associação entre comportamentos desviantes no trabalho e ruptura de certo senso de moralidade que deve permear o setor público, isto é, a necessidade de que a atuação administrativa, para além da observância da lei, siga princípios éticos gerais de boa-fé, honestidade e atendimento ao interesse público. Trata-se, assim, do entendimento do desvio em sua acepção negativa.

Além disso, a descrição dada pelos entrevistados aproxima a ocorrência de comportamentos desviantes ao conceito de organização de indivíduos corruptos, no qual condutas individuais de desvio são frequentes e disseminadas pela organização, tendo como propósito primordial a obtenção de benefícios em nome próprio (Pinto et al., 2008).

\subsection{Pactos de silêncio e censura}

Os respondentes revelaram a existência de um ambiente organizacional no qual, a fim de manter a coesão das unidades setoriais ou a imagem de certos indivíduos ou grupos, o posicionamento padrão da organização é negar ou ignorar a ocorrência de condutas e práticas adversas como parte da realidade organizacional. Tem-se, assim, um entendimento de privacidade das questões que envolvem atos de corrupção, de forma que intervenções de superiores ou órgãos responsáveis, para lidar com o fenômeno, são vistas como potencialmente intrusivas ou até mesmo ofensivas à autoridade dos servidores à frente da equipe ou setor onde tenha ocorrido o desvio, como coordenadores, superintendentes e supervisores:

Existe uma tendência que isso melhore, mas eu não vejo, não consigo perceber que isso hoje é tratado de forma adequada, não. Que isso não é tratado abertamente, não é conversado, é meio que querer tampar um sol com a peneira, por enquanto. [...] Nunca vi em momento nenhum, em quatro anos de instituição, se tratar disso, em momento algum (Servidor da área de segurança pública 2).

[...] seria interessante porque a gente sempre tem muito curso, muito seminário, palestra voltada para a gestão, muita coisa voltada pra essa coisa técnica, mas sobre esse tema não. [...] Nunca participei, não vi acontecendo... É interessante, você falando assim, realmente. Não é um assunto muito abordado, não, pelo menos nos locais onde eu trabalhei. Nunca foi (Servidor da área da saúde).

Um desdobramento importante desse silêncio é a ausência de clareza em relação a diretrizes sobre comportamentos e atitudes esperadas do servidor. A despeito da existência de normas gerais sobre conduta ética de servidores, raramente há detalhamento das práticas de gestão ou das atividades a serem desempenhadas. Dessa maneira, criam-se oportunidades para a manifestação de comportamentos desviantes ou disfuncionais, uma vez que não há proibição explícita para sua prática:

Orientação com relação à corrupção, não. Do que seria esse desvio de conduta do servidor. Desde que eu entrei no estado eu nunca recebi nenhuma orientação, e assim mesmo tem uma grande dificuldade de receber orientação de como você vai executar as suas atividades. Muitas vezes você chega em um setor, resultado de um processo seletivo de qualquer via, e você entra naquele determinado setor achando que você vai executar determinada atividade, e muitas vezes o que você acaba fazendo é outro tipo de atividade, não existe uma orientação correta do que você vai executar. [...] $\underline{O}$ chefe muitas vezes não tem consciência do que ele quer do servidor, o que dificulta também você dar um conceito para o que é corrupção ou para o que é um desvio de conduta do servidor. [...] Tem alguma diretriz, algum procedimento, alguma coisa que é adotada? Não; você nunca sabe quando tomar essa decisão, você nunca sabe como fazer, e as pessoas sabem que não existe, os servidores sabem que isso não existe, então muitas vezes elas usam disso para a coisa não ir pra frente (Servidor da área de segurança pública 1). 
Os trechos acima indicam que a prática de comportamentos desviantes é favorecida por um ambiente onde não existem regras internas bem disseminadas, nem para os comportamentos, nem para métodos de trabalho. Tais condições constituem uma autorização implícita ou uma brecha a ser explorada, a despeito de eventuais desdobramentos negativos para a organização, seus membros ou beneficiários do serviço público.

\subsection{A "rádio peão"}

Apesar de o posicionamento “oficial” da organização ser a manutenção de certo 'silêncio' quando se trata de práticas de corrupção, isso não significa dizer que informações sobre tais condutas não circulem internamente. Pelo contrário, servidores reconhecem um mecanismo não oficial e oficioso de disseminação de informações: a 'rádio peão'. O nome vem do antigo sistema de difusão de informação, o rádio, e de um dos principais locais de origem de boatos e rumores organizacionais: a sua base operacional, onde se concentra o maior número de funcionários, nesse caso, denominados “peão” (Cardoso, 1995):

\section{Já ouvi sim, mas só de conversa, nada que eu presenciei ou chegou mais próximo. Mas de o pessoal falar "aconteceu isso, aconteceu isso com fulano, fulano fez isso", isso aí sim, rádio peão o tempo inteiro. Você ouve falar. [...] O pessoal comenta sim, mas ninguém trata isso de forma aberta, é só um bochicho... Aí se for uma coisa mais grave você vê no jornal. Aí comenta... Às vezes se tem uma punição você vê no Diário [Oficial] (Servidor da área da saúde). \\ Pelo meu sentimento, é a rádio peão. Isso não é formalizado, ninguém divulga, é varrido normalmente pra debaixo do tapete, pra não mostrar mesmo. [...] Só que isso, formalmente, na organização, não é comentado. É a rádio peão que comenta. Pela alta administração, pelas chefias, nunca vi qualquer tipo de comentário (Servidor da área de segurança pública 2).}

A “programação” da 'rádio peão' é frequente, mas bastante diversificada, e os assuntos são levantados de maneira desordenada. Além disso, percebe-se que a 'rádio peão' não está restrita a setores específicos, se difundindo por toda a estrutura organizacional. Ela se materializa nas conversas de corredor, que acontecem no 'intervalo do cafezinho' e até em encontros fora do horário de expediente e do ambiente de trabalho.

Conforme relatado pelos entrevistados, apesar de os assuntos serem encarados com cautela, visto haver a possibilidade de as informações serem inverídicas ou distorcidas, em várias ocasiões os rumores se mostraram verdadeiros. Com relação a práticas de corrupção, alguns tipos são mais comuns:

[...] troca de favor com contratos, troca de favor pessoal, vantagens pessoais em contratos, troca de favores até mesmo de "ah, não, eu vou te dar uma assistência policial aqui, vou te dar uma cobertura", almoço de graça em restaurante, utilização de viaturas e equipamentos pra uso pessoal, esses desvios de bens apreendidos, venda de carteira de motorista, infelizmente a gente ainda ouve falar, apesar de todo o esforço da administração para que isso não aconteça. [...] Essas práticas menores a gente escuta na rádio peão, para as coisas maiores, a rádio peão talvez não tenha nem acesso, não há um comentário nesse sentido, mas essas pequenas, mas não menos erradas práticas, são as mais comentadas (Servidor da área de segurança pública 2).

Eu já ouvi falar na saúde caso de urgência e emergência... Favorecimento pra vender sistema para unidade de saúde. Às vezes tem uma companhia que domina esse tipo de tecnologia, algum termo de parceria, formação de cartel, alguma coisa nesse sentido. A entidade parceira desviando em forma de consultoria, essas coisas (Servidor da área de saúde).

Em vista disso, são feitas duas observações. Primeiro, a 'rádio peão' oferece um interessante contraponto ao posicionamento padrão da organização de neutralizar e silenciar a prática de condutas desviantes, tornando a ocorrência destes comportamentos mais visível, ainda que de forma assistemática. Segundo, a fragilidade das evidências sobre comportamentos desviantes fomenta um tratamento igualmente informal e assistemático.

\subsection{Mecanismos persecutórios, retaliatórios e de diferenciação}

Apesar de terem relatado ou vivenciado episódios de condutas desviantes, os entrevistados afirmaram jamais terem formalizado uma denúncia, seja por ausência de provas mais concretas ou por medo de eventual exposição: 
Formalmente, não, porque todas essas coisas que a gente às vezes toma conhecimento, eu não tenho como provar. São situações que às vezes você realmente não tem como dar andamento. [...] Informalmente, já. Essa questão mesmo de alocação de servidor. Já vi e já relatei casos de alocação de servidor a bel prazer, assim, "eu quero colocar o servidor lá e pronto". Não é porque a unidade precisa. Então esse tipo de prática eu já fiz relato, já fiz relatos de até situações suspeitas, de ver pessoas fora do horário de expediente, descendo às escondidas pelo elevador com documentação da instituição, levando embora pra fazer sei lá o quê. Informalmente já informei [...].

Nesse caso dos documentos, foi averiguado, foi feita uma investigação e confirmou que tinha realmente levado, e o que não era de direito da pessoa levar retornou para a instituição. Então, assim, eu fiquei satisfeito com esse resultado (Servidor da área de segurança pública 2).

Não é uma coisa que dá pra você formalizar uma denúncia, é muito frágil. É igual o que eu te falei, o pessoal não vai entrar em detalhes. Ás vezes tá perto, é uma pessoa que trabalha no setor, então fica difícil. [...] O pessoal às vezes manda pra ouvidoria, manda pra imprensa... (Servidor da área da saúde).

O relato dos entrevistados sugere que a probabilidade de comportamentos desviantes serem identificados e discutidos dependerá, em grande medida, da disposição dos responsáveis pela averiguação, como chefes imediatos, coordenadores de equipe, dentre outros; e da relação de (des)confiança entre estes e os envolvidos, tanto com relação ao delator quanto em relação ao denunciado. Disso resulta uma abordagem muito diferenciada para comportamentos semelhantes, e ausência de critérios sobre a escolha de um ou outro curso de ação:

Se tiver muito perto as pessoas não ficam à vontade de falar, porque às vezes é amigo de um, conhecido de outro, então não é fácil falar sobre isso, não (Servidor da área da saúde).

Até fatores sérios que acontecem na organização, em vez de levar pra corregedoria, seguir um processo administrativo, o que eu vejo muito e isso é real, é afastam a pessoa, dão um jeito de ela aposentar, troca a pessoa de setor, mas de uma forma que não é assim, uma punição pra pessoa evoluir, é uma punição assim, "vou te tirar de cena, para as pessoas te esquecerem, depois, se der, a gente te coloca [de volta]". Você acha que aquilo serviu de lição, até para melhorar, criar um procedimento, isso que você está perguntando? Isso não tem (Servidor da área de segurança pública 1).

Nesse aspecto, vê-se que notificar a ocorrência de comportamentos desviantes pode resultar em problemas, os quais, em grande medida, são resultado do despreparo das organizações que as recebem. Este contexto pode levar a não responsabilização dos indivíduos cujo comportamento seja desviante, ou a não proteção ou prejuízo para os informantes destes comportamentos, reforçando novamente o silêncio já referido. A imprevisibilidade da abordagem em relação a situações de comportamento desviante está relacionada, conforme relatos, ao receio de servidores se envolverem nestas situações:

[A pessoa] tem que avaliar se vai sofrer alguma retaliação, ou não. Imagina que você está em um setor e você está vendo que está acontecendo alguma coisa. Você vai falar pro seu chefe? Você não sabe se o seu chefe é amigo do outro lá... É complexo. Porque se estiver muito próximo de você, envolvendo essas pessoas, pessoas com quem você trabalha, fica difícil. [...] A pessoa não tem proteção, ela pode sofrer retaliação de várias formas, o risco que ela corre de falar alguma coisa, de denunciar, pode ser que ela fique muito prejudicada (Servidor da área de saúde).

Sobre este ponto, ressalta-se, ainda, a menção muito superficial a mecanismos formais de controle, tanto internos quanto externos. Órgãos como Controladoria Geral e auditorias setoriais, que são unidades internas de controle e acompanhamento, sequer foram citados. Já o Tribunal de Contas, Ministério Público e Ouvidoria foram mencionados por um dos respondentes como exemplos de atuação mais pontual, para os casos de desvios mais graves ou de grande repercussão. Outros canais, como a Corregedoria e o setor de recursos humanos, quando mencionados, o foram com certa suspeição, como se tais mecanismos não pudessem ser vistos como alternativas efetivamente viáveis para denúncia de comportamentos desviantes:

[...] acho que poderia ser um caminho, um lugar que a pessoa pudesse procurar sabendo que ela teria certo respaldo, que ela não vai ser exposta, pra escutar o servidor. O problema é que essa unidade tem que ser independente mesmo, pra não expor o servidor (Servidor da área de saúde).

Se eu tivesse uma situação concreta, eu levaria. Eu levaria, mesmo sabendo de casos passados e presenciados que a pessoa que faça esse tipo de delação, de entrega de um comportamento desse tipo ela pode ser ela própria prejudicada e perseguida, de alguma forma prejudicada. Mesmo sabendo que isso pode acontecer eu faria o meu relato, formalizaria um relato, mas se eu tivesse realmente como provar (Servidor da área de segurança pública 2).

As falas dos entrevistados insinuam certa desconfiança quanto à transparência, neutralidade e garantia de sigilo na condução dos trabalhos de apuração de comportamentos desviantes. 
Tal visão é bastante significativa, considerando-se os avanços das instituições de controle no Brasil, a exemplo de reformas administrativas e ampliação de funções (Filgueiras \& Aranha, 2011; Oliveira Júnior, Costa \& Mendes, 2016). Talvez, os episódios passados de tratamento muito distintos para condutas semelhantes, pelas vias informais, e falta de diretrizes internas claras contribuam para que essa percepção de que não há saída segura para tratar do assunto se estenda aos órgãos formais de controle. Um dos entrevistados chegou a mencionar falta de maturidade na atuação dos órgãos de fiscalização.

De forma complementar, o trecho abaixo sugere que as pessoas que informam sobre práticas de corrupção nas organizações, em lugar de serem vistas como servidores preocupados com o andamento dos trabalhos, processos e métodos, são vistas como "causadoras de problemas", isto é, estão se envolvendo em algo que não deveriam. Neste sentido, assim como os desviantes, também precisariam ser silenciadas:

Eu presenciei um fato que realmente aconteceu. Uma servidora fez um relato de uma situação que inclusive ela tinha como provar, e foi desligada da instituição, como quem diz "aqui você não mexe", "não mexa no que você não tem direito de mexer, então tchau". [...] Infelizmente, as pessoas lidam com o certo e com o errado de acordo com o que passa na cabeça delas. Principalmente aquelas pessoas que estão na instituição há muitos anos, esse é o meu sentimento, as que estão na instituição há muitos anos têm uma tendência a meio que proteger a instituição, então nisso aqui ninguém mexe, ninguém fala que está errado, "eu não fiz errado", em vez de falar sobre o problema, que é o que eu tenho visto atualmente. [...] Só falando do problema é que a gente resolve. Então na ocasião em que aconteceu este problema, quem estava à frente, não é que não tivesse interesse em resolver, porque a pessoa que estava errada, a pessoa da qual a situação foi levantada, a pessoa foi punida, mas quem levantou também foi, até antes de quem tinha praticado o ato ilegal. Mas era o pensamento, "não mexe na minha caixinha de abelhas que você vai ser picado" (Servidor da área de segurança pública 2).

A fim de manter o silêncio sobre práticas desviantes, lança-se mão de diversos mecanismos, que parecem variar conforme o tipo de vínculo funcional do servidor. Para servidores não estáveis, como os comissionados, os ocupantes de cargo de recrutamento amplo, contratados especiais, dentre outros, a ameaça de desligamento do setor público tende a predominar. Por outro lado, para servidores estáveis, como concursados, efetivos e efetivados, há uma peculiaridade: o chefe ou superior hierárquico não dispõe sobre o vínculo funcional deste servidor, não podendo, portanto, demiti-lo, a não ser nos casos previstos em lei. Em vista disso, relatou-se a ocorrência de manobras para desqualificação do trabalhador ou do trabalho:

[A pessoa] pode perder um cargo, uma função... Ela vai fazer um trabalho sem muita relevância. [...] Você ser relegado a trabalhos menores, outros trabalhos, ir pra outro setor, nesse sentido. Não conseguir sair do lugar onde você está... Por exemplo, você está em um lugar muito ruim, a pessoa te colocou ali e você vai ficar ali... Várias formas de dificultar sua vida. Isso tem demais (Servidor da área da saúde).

Outro elemento a ser ressaltado é o fato de, no setor público, os chefes ou gestores não serem, em alguns casos, indicados em função de sua qualificação técnica e experiência ou preparo para o desempenho das atividades, e sim por decorrência de laços de amizade ou relações políticas. Em vista disso, pode haver fragilidades nas relações entre estes gestores e suas equipes, seja por ausência de confiança, seja pela própria conduta do chefe, ao abusar de sua autoridade ou dos vínculos que o mantém naquela posição:

[...] a pessoa filiada de um partido pode gerar desconfiança "ah, fulano de tal é de tal partido, não vai poder ficar nesse cargo de chefia". Às vezes é uma pessoa boa tecnicamente. A questão do afeto, a questão da vinculação partidária. Não precisa ser a coisa da denúncia, não precisa ser algo mais grave pra ocorrer isso. Às vezes só o fato da amizade, porque brigou, dependendo se a pessoa é dada a essas coisas, retaliar (Servidor da área da saúde).

Aqui é possível estabelecer uma conexão entre tais comportamentos e a literatura que trata de clientelismo, patronagem, favoritismo, dentre outros fenômenos conexos, como característicos da burocracia brasileira. Diversos estudos (Ottmann, 2006; Raupp, \& Pinho, 2012; Oliveira, Oliveira \& Santos, 2011; Oliveira Júnior et al., 2016) abordaram como estes fenômenos impactam nos processos de canalização de demandas, estabelecimento de prioridades e distribuição de recursos materiais e imateriais, atuação esta que pode conflitar com o senso de moralidade ou imparcialidade esperado na prestação dos serviços públicos e no tratamento de seus servidores.

Em vista do que foi abordado, pode-se dizer que o material coletado por meio das entrevistas oferece considerações importantes sobre comportamentos desviantes considerados corruptos, extrapolando a acepção jurídico-normativa de tais condutas. Nesse sentido, mesmo os pequenos desvios, categorizados como tais por Robinson e Bennett (1995), seriam agravados por ocorrerem no setor público. Tais desvios se estabelecem e se perpetuam em um contexto organizacional de silêncio e negação de práticas de corrupção, em particular por setores e grupos da alta administração. 
Busca-se garantir que a realidade da vida organizacional não venha a público, seja rejeitando a existência de práticas de corrupção, seja dando a elas tratamento inadequado ou inconsistente. Tais resultados estão em consonância com as observações de Filgueiras e Aranha (2011), que relacionam discricionariedade e ausência de procedimentos e regras universais à perpetuação da corrupção como prática na administração pública.

Nesse sentido, é possível perceber convergências também com o assédio moral no trabalho, caso a desqualificação das atividades e da pessoa se deem de maneira repetitiva, persistente e continuada. Segundo Martiningo Filho e Siqueira (2008), a falta de clareza quanto a demandas e expectativas, formas de encarar conflitos e ambiguidades, e falta de suporte da alta administração, que abdica da responsabilidade e não intervém em situações de desvio, tais como as descritas neste estudo, são fatores para a prevalência de assédio moral no trabalho. Poderia haver, assim, articulações importantes entre práticas de corrupção e seus efeitos em certos aspectos do trabalho, como motivação, stress e satisfação. O clima de medo e silêncio abre possibilidades para marginalização, isolamento e até rompimento do vínculo de trabalho daqueles que decidem falar sobre comportamentos desviantes.

A menção de um dos entrevistados de que estes comportamentos estão arraigados na cultura organizacional indica uma aceitação tácita de tais práticas como parte indesejável, porém, inevitável do cotidiano da organização. Observa-se, assim, um posicionamento dúbio por parte do servidor: de um lado, reconhece que tais comportamentos ofendem certas expectativas que permeiam a esfera pública; de outro, busca não se envolver ou não criar animosidades quando em face de atos considerados corruptos, abrindo espaço para que tais práticas sejam toleradas ou consideradas toleráveis (Filgueiras, 2009).

Os dados coletados também explicitam certas táticas de racionalização e socialização sobre corrupção (Anand et al., 2005), entendidas como os processos pelos quais os indivíduos produzem sentido de suas ações de forma a não percebê-las como incorretas, ilegais ou imorais. Dessa maneira, a atitude dos servidores seria influenciada por diversos fatores, tais como precedentes institucionais, rotinas, pressão de grupos ou superiores e dilemas de ordem emocional ou afetiva que poderiam levar a aceitação e perpetuação de práticas de corrupção. Algumas das táticas mencionadas por Anand et al. (2005) são: a negação de responsabilidade - "eu não tive escolha", "todo mundo faz" e "eu não tenho nada a ver com isso"; a negação do dano - "ninguém foi prejudicado", "tem piores do que eu"; e apelo a lealdades - para com o grupo, com o chefe ou com a própria organização. A visão de que a corrupção é um fenômeno generalizado, por exemplo, poderia ser considerada negação de responsabilidade. Assim, táticas de racionalização e socialização poderiam ser empregadas para que comportamentos desviantes sejam vistos como normais.

\section{CONSIDERAÇÕES FINAIS}

Os resultados apresentados neste trabalho revelam alguns aspectos da dinâmica entre corrupção, percepções sobre corrupção e comportamentos desviantes, além de apontar possíveis linhas para investigação mais aprofundada de padrões de comportamentos organizacionais associados à corrupção. Dessa maneira, podem contribuir para a reflexão e ampliação de pesquisas que tratem de: comportamentos negativos como parte das práticas organizacionais ('dark side’ das organizações), capacitação dos agentes públicos para o exercício de suas funções, e percepções sobre a atuação de órgãos fiscalizadores e de controle.

As entrevistas sugerem que a corrupção não estaria adstrita ao ato pontual de determinado servidor, mas a uma rede difusa de comportamentos e atitudes, muitas vezes legais, que interagem para a continuidade de certas práticas percebidas como indevidas, com tratamento diferenciado entre servidores e imprevisibilidade quanto à aplicação de sanções para determinado tipo de ato.

A identificação de alguns destes mecanismos pelos quais comportamentos desviantes e práticas de corrupção se inter-relacionam e se sobrepõem apontam para a necessidade de se aprofundar estudos sobre redes organizacionais informais, a fim de melhor compreender os códigos latentes de silêncio sobre o cotidiano organizacional; dinâmicas de lealdade e cumplicidade que levam a tratamento diferenciado de servidores e das tarefas que estes desempenham; a internalização, racionalização e replicação de ações consideradas corruptas; e associação entre comportamentos desviantes e a atuação de canais formais de denúncia.

Considerando as limitações deste trabalho e relativa escassez de estudos que abordam corrupção no setor público para além de seu aspecto jurídico-normativo, é pertinente a realização de pesquisas complementares, as quais poderão contribuir para um melhor conhecimento sobre o tema e suas implicações nas organizações públicas. 


\section{REFERÊNCIAS}

Anand, V., Ashforth, B., \& Joshi, M. (2005). Business as usual: the acceptance and perpetuation of corruption in organizations. The Academy of Management Executive, 19(4), p.9-23.

Appelbaum, S. H., Iaconi, G. D., \& Matousek, A. (2007). Positive and negative deviant workplace behaviors: causes, imapcts, and solutions. Corporate Governance, 7(5), p.586-598.

Ashforth, B., Gioia, D., Robinson, S., Treviño, L. (2008). Re-viewing organizational corruption. Academy of Management Review, 33(3), p.670-684.

Brei, Z. A. (1996). Corrupção: dificuldades para definição e para um consenso. Revista de Administração Pública, 30(1), p.64-77.

Cardoso, M. S. (1995). Rádio peão: estudo dos mecanismos, tipologias e os efeitos dos rumores nas organizações. Dissertação de mestrado, Escola de Administração de Empresas de São Paulo, Fundação Getúlio Vargas, São Paulo, Brasil.

Filgueiras, F. (2004). Notas críticas sobre o conceito de corrupção: um debate com juristas, sociólogos e economistas. Revista de Informação Legislativa, 41(64), p.125-148.

Filgueiras, F. (2009). A tolerância à corrupção no Brasil: uma antinomina entre normas morais e prática social. Opinião Pública, 15(2), p.386-421.

Filgueiras, F., \& Aranha, A. L. M. (2011). Controle da corrupção e burocracia da linha de frente: regras, discricionariedade e reformas no Brasil. DADOS - Revista de Ciências Sociais, 54(2), P.349-387.

Martiningo Filho, A., \& Siqueira, M. V. S. (2008). Assédio moral e gestão de pessoas: uma análise do assédio moral nas organizações e o papel da área de gestão de pessoas. Revista de Administração Mackenzie, 9(5), P.11-34.

Oliveira Júnior, T. M., Costa, F. J. L. da \& Mendes, A. P. (2016). Perspectivas teóricas da corrupção no campo da administração pública brasileira: características, limites e alternativas. Revista Serviço Público, 67(especial), p.111-138

Oliveira, R. F., Oliveira, V. C. da S. \& Santos, A. C. dos. (2011). Beneficiários ou reféns? O patrimonialismo na perspectiva dos cidadãos de Poço Fundo, Minas Gerais. Cadernos EBAPE.BR, 9(4), p.950-966.

Ottmann, G. (2006). Cidadania mediada: processos de democratização da política municipal no Brasil. Novos Estudos - CEBRAP, 74, p.155-175.

Pinto, J., Leana, C., \& Pil, F. (2008). Corrupt organizations or organizations of corrupt individuals? Two types of organization-level corruption. Academy of Management Review, 33(3), p.685-709.

Raupp, F. M., \& Pinho, J. A. G. (2012). Ensaio teórico sobre a presença do patrimonialismo no Poder Legislativo local. Administração Pública e Gestão Social, 4(3), p.296-292.

Robinson, S., \& Bennett, R. (1995). A typology of deviant workplace behaviors: a multidimensional scaling study. Academy of Management Journal, 38(2), p.555-572.

Spreitzer, G., \& Sonenshein, S. (2004). Toward the construct definition of positive deviance. American Behavioral Scientist, 47(6), p.828-847.

Warren, D. E. (2003). Constructive and destructive deviance in organizations. Academy of Management Review, 28(4), p.622-632. 